\title{
North American Primary Care Research Group President's Award
}

\section{Dr. Puffer and the American Board of Family Medicine Receive the North American Primary Care Research Group President's Award}

At the October 2007 annual meeting of the North American Primary Care Research Group (NAPCRG) in Vancouver, British Columbia, Canada, the NAPCRG President's Award was presented to James Puffer, MD, and to the American Board of Family Medicine (ABFM). The award was made "in recognition of their support of publishing family medicine research, through the Fournal of the American Board of Family Medicine ( $7 A B F M)$ and the Annals of Family Medicine." Dr. Puffer is the Executive Editor of the $7 A B F M$ and the President and Chief Executive Officer of the ABFM. The following is text of the presentation speech made by $W$. Perry Dickinson, MD, current NAPCRG President.

"A number of years ago the ABFM took note of the fact that there was an inadequate number of journals in which family medicine research could be published and read. In response to this problem, they took action and began the fournal of the American Board of Family Medicine. Approximately 6 years ago, in response to shifts in some of our other family medicine journals, we were able to highlight for all of our organizations the need for a premier primary care research journal as a place to publish and highlight the best work of our researchers, and the ABFM once again came forward and took a large role in financially supporting the formation of the Annals of Family Medicine. At that time, there was an expectation that they would probably close down the $7 A B F M$, but their board was concerned that, with the continued overall expansion of our research efforts, it would still leave inadequate places to publish our research, so they kept it going. The wisdom of that is apparent in both the great success of the Annals and the growing role of the $7 A B F M$ as a great and important place for the publication of family medicine research. Obviously several of the organizations contributing to the Annals also have their own journals, but the amount of resources and support that the ABFM has put into publishing original primary care research is unmatched and is greatly appreciated. I would like to

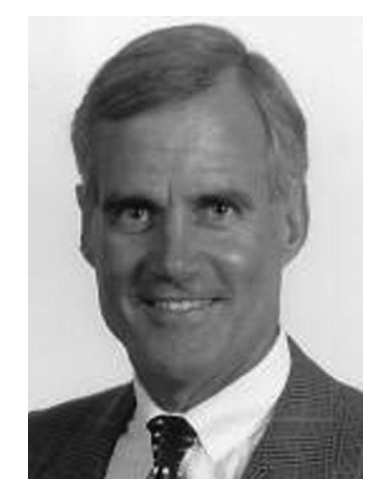

James Puffer, MD, President and Chief Executive Officer of the ABFM and Executive Editor of the JABFM.

present a President's Recognition Award to Jim Puffer, MD, the Executive Director of the Board, for his leadership of the Board but also to the ABFM in general for their great and somewhat unrecognized support of the publication of our research."

\section{JABFM Featured on the Web}

7ABFM articles are often featured, abstracted, or otherwise mentioned in print or on the Internet. Below are examples of where we have seen our articles during 2007. Authors are encouraged to notify the 7ABFM editorial office (jabfm@med.wayne.edu) about sightings or mention of their articles on the Internet or in other media.

Featured in the "Family Medicine Updates" section of the Annals of Family Medicine, 2007;5(1):91-92.

- Cain JJ, et al. Family physicians and youth tobacco-free education: outcomes of the Colorado Tar Wars program. ${ }^{1}$

Featured in MDLinx (http://www.mdlinx.com/):

- Arnold JG, McGowan HJ. Delay in diagnosis of diabetes mellitus due to inaccurate use of hemoglobin $\mathrm{A}_{1 \mathrm{C}}$ levels. ${ }^{2}$

- Dunlop AL, et al. National recommendations for preconception care: the essential role of the family physician. $^{3}$ 
- Leeman LM, et al. Do unsutured second-degree perineal lacerations affect postpartum functional outcomes? $^{4}$

- Petkar N, et al. High-rising epiglottis in children: should it cause concern? ${ }^{5}$

Featured in the US Department of Health and Human Services, Agency for Health Research and Quality Research Activities newsletter (ie, November 2006, July 2007, and October 2007) (http://www. ahrq.gov/):

- Elder NC, et al. Barriers and motivators for making error reports from family medicine offices: a report from the American Academy of Family Physicians National Research Network (AAFP NRN). ${ }^{6}$

- Gaskins ND, et al. Poor nutritional habits: a modifiable predecessor of chronic illness? A North Carolina Family Medicine Research Network (NC-FM-RN) study. ${ }^{7}$

- Hartz A, James PA. A systematic review of studies comparing myocardial infarction mortality for generalists and specialists: lessons for research and health policy. ${ }^{8}$

- Kuo GM, et al. Cross-sectional comparison of electronic and paper medical records on medication counseling in primary care clinics: a Southern Primary-care Urban Research Network (SPUR-Net) study. ${ }^{9}$

- Ralston S, et al. Practice-based assessment of tobacco usage in southwestern primary care patients: a Research Involving Outpatient Settings Network (RIOS Net) study. ${ }^{10}$

- Rust G, Cooper LA. How can practice-based research contribute to the elimination of health disparities? $^{11}$

Featured on Journal Watch (http://firstwatch. jwatch.org/cgi/content/full/2006/1214/2) as well as their Physicians' First Watch (http:firstwatch. jwatch.org/cgi/archive):

- Ely JW, Kennedy CM, Clark EC, Bowdler NC. Abnormal uterine bleeding: a management algorithm. $^{12}$

\section{Another Exciting Issue of the JABFM}

The topic of publishing by family medicine authors has continued to be important to our family phy- sician academicians, those who train our future family physicians and provide new information to guide our practice. ${ }^{13,14}$ We have several journals dedicated to family medicine, with a limited number of pages, and an increasing number of welltrained and inquisitive family medicine researchers. Thankfully, there are other avenues and other journals in which family physicians can and should publish. We are proud that the $7 A B F M$ and the Fournal of Women's Health (which MAB edited in 2000-2005) were among the top journals publishing family medicine research.

Wittink ${ }^{15}$ provides us with provocative new data on a previously unreported factor for recommendation of mammography: The level of anxiety of the patient as identified by the physician. Is it appropriate for this factor to affect physician recommendations? Were anxious patients more likely to recall physician recommendations? Kemp et $\mathrm{al}^{16}$ find that patients prefer physicians to assess their understanding of recommendations in a collaborative fashion, something that feels quite true in practice and should inform our teaching practices.

We have 2 articles related to immunizations, an extremely common activity in family physician offices. Ferris ${ }^{17}$ is pursuing the issue of the human papillomavirus vaccine, currently recommended up to age 26. What do older, mid-life women think? One of the findings is that women who have had an abnormal Papanicolaou smear were more interested in getting a vaccine, yet currently the efficacy and effectiveness for mid-life women and those with previous abnormal Papanicolaou smears is unknown. However the survey does suggest that increasing awareness of the association of the human papillomavirus and cervical cancer can increase the willingness of women to be vaccinated, so education (perhaps learned the hard way by women with previously abnormal Papanicolaou smears) is key. In addition, family physicians can increase the rate of getting vaccines appropriately completed by implementing standing orders. ${ }^{18}$

There are 2 clinical reviews this month. Lessenger ${ }^{19}$ reminds us that over-the-counter medicines can be abused, something we may often fail to ask about or consider; we have no equivalent to the recognized screening questionnaires we use to detect alcoholism or depression. A second clinical review reminds us that diesel exhaust can also have wide ranging health implications. ${ }^{20}$ Remembering to note occupation and the potential exposures could help family physicians prevent issues for individual patients; we also need to 
work politically to improve the environment for everyone. Think GREEN.

Also in this month's issue of $\mathcal{A} A B F M$, a family physician $^{21}$ who works in palliative care suggests something unexpected in a provocative "reflections" piece: pregnancy care helping a physician when providing end-of-life care as well; birth and death provide dramatic transitions. This issue's Brief Reports provide a reminder on primary meningococcal arthritis ${ }^{22}$ and unique cases of clozapine-induced cardiomyopathy ${ }^{23}$ and concurrent babesia and lyme disease after splenectomy. ${ }^{24}$

This issue of the journal highlights exactly the type of information family medicine researchers are providing to influence practice. From the common to the rare individual case reports or large research studies in the community, and issues affecting both individuals and public health, this issue is an excellent example of the range of family physician publications.

Marjorie A. Bowman, MD, MPA

Anne Victoria Neale, PhD, MPH

\section{References}

1. Cain JJ, Dickinson WP, Fernald D, Bublitz C, Dickinson LM, West D. Family physicians and youth tobacco-free education: outcomes of the Colorado Tar Wars program. J Am Board Fam Med 2006;19: 579-89.

2. Arnold JG, McGowan HJ. Delay in diagnosis of diabetes mellitus due to inaccurate use of hemoglobin $\mathrm{A}_{1 \mathrm{C}}$ levels. J Am Board Fam Med 2007;20:93-6.

3. Dunlop AL, Jack B, Frey K. National recommendations for preconception care: the essential role of the family physician. J Am Board Fam Med 2007;20:81-4.

4. Leeman LM, Rogers RG, Greulich B, Albers LL. Do unsutured second-degree perineal lacerations affect postpartum functional outcomes? J Am Board Fam Med 2007;20:451-7.

5. Petkar N, Georgalas C, Bhattacharyya A. High-rising epiglottis in children: should it cause concern? J Am Board Fam Med 2007;20:495-6.

6. Elder NC, Graham D, Brandt E, Hickner J. Barriers and motivators for making error reports from family medicine offices: a report from the American Academy of Family Physicians National Research Network (AAFP NRN). J Am Board Fam Med 2007;20:115-23.

7. Gaskins ND, Sloane PD, Mitchell CM, et al. Poor nutritional habits: a modifiable predecessor of chronic illness? A North Carolina Family Medicine Research Network (NC-FM-RN) study. J Am Board Fam Med 2007;20:124-34.

8. Hartz A, James PA. A systematic review of studies comparing myocardial infarction mortality for generalists and specialists: lessons for research and health policy. J Am Board Fam Med 2006;19:291-302.

9. Kuo GM, Mullen PD, McQueen A, et al. Cross-sectional comparison of electronic and paper medical records on medication counseling in primary care clinics: a Southern Primary-care Urban Research Network (SPUR-Net) study. J Am Board Fam Med 2007;20: 164-73.

10. Ralston S, Kellett N, Williams RL, Schmitt C, North CQ. Practice-based assessment of tobacco usage in southwestern primary care patients: a Research Involving Outpatient Settings Network (RIOS Net) study. J Am Board Fam Med 2007;20:174-80.

11. Rust G, Cooper LA. How can practice-based research contribute to the elimination of health disparities? J Am Board Fam Med 2007;20:105-14.

12. Ely JW, Kennedy CM, Clark EC, Bowdler NC. Abnormal uterine bleeding: a management algorithm. J Am Board Fam Med 2006;19:590-602.

13. Hueston WJ. Research activity in family medicine: the "best of times" or "can I have more, please"? J Am Board Fam Med 2008;21:4-5.

14. Pathman DE, Viera AJ, Newton WP. Research published in 2003 by US family medicine authors. J Am Board Fam Med 2008;21:6-16.

15. Wittink MN, Bogner HR. Primary care physicians' assessments of older patients' health and psychological status and recommendation of mammography. J Am Board Fam Med 2008;21:17-23.

16. Kemp EC, Floyd MR, McCord-Duncan E, Lang F. Patients prefer the method of "tell back-collaborative inquiry" to assess understanding of medical information. J Am Board Fam Med 2008;21:24-30.

17. Ferris DG, Waller JL, Owen A, Smith J. HPV vaccine acceptance among mid-adult women. J Am Board Fam Med 2008;21:31-37.

18. Gamble GR, Goldstein AO, Bearman RS. Implementing a standing order immunization policy: a minimalist intervention. J Am Board Fam Med 2008;21:38-44.

19. Lessenger JE, Feinberg SD. Abuse of prescription and over-the-counter medications. J Am Board Fam Med 2008;21:45-54.

20. Krivoshto IN, Richards JR, Albertson TE, Derlet RW. The toxicity of diesel exhaust: implications for primary care. J Am Board Fam Med 2008;21:55-62.

21. Clark WD. Pregnancy care: an apprenticeship for palliative care? J Am Board Fam Med 2008;21:63-65.

22. Harwood MI, Womack J, Kapur R. Primary meningococcal arthritis. J Am Board Fam Med 2008;21:66-69.

23. Pastor CA, Mehta M. Masked clozapine-induced cardiomyopathy. J Am Board Fam Med 2008;21:70-74.

24. Abrams Y. Complications of coinfection with babesia and Lyme disease in a man with splenectomy. J Am Board Fam Med 2008;21:75-77. 